\title{
Isomerization of $\beta$-Pinene Oxide over Sn-modified Zeolites
}

\author{
P. Mäki-Arvela ${ }^{a}$, N. Kumara ${ }^{a}$ S. Faten Diáz ${ }^{a}$, A. Aho ${ }^{a}$, M. Tenhob ${ }^{b}$ J. Salonen ${ }^{b}$,
}

\author{
A.-R. Leinoc, K. Kordás ${ }^{c}$, P. Laukkanend ${ }^{d}$ J. Dahl ${ }^{d}$, I. Sinev ${ }^{e}$ T. Salmi ${ }^{a}$, D. Yu. Murzin ${ }^{\mathrm{a}}$ \\ ${ }^{a}$ Process Chemistry Centre, Åbo Akademi University, Turku, Finland \\ ${ }^{b}$ University of Turku, Turku, Department of Physics, Turku, Finland \\ ${ }^{c}$ University of Oulu, Microelectronics Microelectronics and Materials Physics Laboratories, \\ FIN-90014 Oulu, Finland \\ ${ }^{d}$ University of Turku, Turku, Finland \\ ${ }^{e}$ University of Ruhr, 44801, Bochum, Germany
}

\begin{abstract}
Four different Sn modified zeolites, namely three Beta zeolites with varying Si/Al ratios together with Sn-Y zeolite were synthesized and characterized by XRD, TEM, SEM, FTIR-pyridine, nitrogen adsorption, XPS and EXAFS. Kinetics in $\beta$-pinene oxidation was studied at $70^{\circ} \mathrm{C}$ in toluene as a solvent with different catalysts. The initial isomerization rate increased with increasing acidity. Complete conversion of $\beta$-pinene oxide was achieved with the three most acidic catalysts in less than 30 min, whereas only $72 \%$ conversion in 1440 min was achieved with the Sn-Beta-300 catalyst exhibiting the lowest acidity. The most selective catalyst to the formation of myrtanal was Sn-Beta-300 giving 64\% selectivity at $72 \%$ conversion. The Sn-Beta-300 catalyst according to XPS exhibited state of $\mathrm{Sn}^{2+}$, whereas according to EXAFS Sn was in the form of $\mathrm{SnO}_{2}$. The formation of perillyl alcohol and myrtenol were catalyzed by catalysts exhibiting large amount of acid sites, whereas myrtanal was formed over Sn-Beta-300 with low amount of acid sites.
\end{abstract}

Keywords: Isomerization, terpene, epoxides, Sn, Zeolites 


\section{Introduction}

Catalytic synthesis of fine chemicals from biomass is an important topic. Several catalytic transformations of terpenes have been recently reviewed [1]. These include isomerization, oxidation, epoxidation, hydration esterification and aldol condensation. The products have found applications as cosmetics, pharmaceuticals and flavors. One important group of compounds are mono terpenes, which are present in relatively large quantities in different tree species and they are separated as by-products form pulping. Pinus Ponderosa, which is common in US and contains very much $\Delta^{3}$-carene (36\%) together with $\beta$-pinene (16 \%), $\alpha$ pinene (10\%) and $12 \%$ limonene in the mono terpene fraction [2]. In comparison Picea abies common in Europe contains 58\% $\alpha$-pinene, $24 \% \beta$-pinene and only $2 \% \Delta^{3}$-carene in the mono terpene fraction [3]. Epoxides of monoterpenes can be isomerized to corresponding aldehydes and alcohols, which have applications as fine chemicals. $\alpha$-pinene oxide isomerization has been intensively studied during recent years [4-12]. There are, however, very few publications available from isomerization of $\beta$-pinene oxide [13, 14]. The valueadded products form $\beta$-pinene oxide are myrtanal, myrtenol and perillyl alcohols. Myrtanal is used as perfumery compound [15]. It is also found in some essential oils, but it is not easily available with a low price [13]. Furthermore, myrtanal exhibits anticeptic properties [13]. In addition to myrtanal perillyl alcohol is used as an antimicrobial agent [16] and myrtenol in fragrances [13].

$\beta$-pinene oxide is prepared via oxidation from $\beta$ - pinene via methylene chloride in the presence of sodium carbonate using peracetic acid as an oxidant at $0^{\circ} \mathrm{C}$ [17]. $\beta$-pinene oxide is a tricyclic molecule and is subjected to high strains. The molecule can be rearranged into less strained products, such as myrtanal, myrtenol and perillyl alcohol. Perillyl alcohol can give other secondary products from the rearrangement of its double bonds. Due to the variety of products formed, the production of myrtanal needs the development of a catalyst to make the process more selective.

The isomerization of $\beta$-pinene oxide can be performed either by homogeneous or heterogeneous catalysis. Since the homogeneous catalyst $\mathrm{ZnBr}_{2}$ is active in the isomerization of $\alpha$-pinene oxide into campholenic aldehyde, it was also studied for the $\beta$-pinene oxide rearrangement. The catalyst showed very high activity but poor selectivity for either myrtanal, myrtenol or perillyl alcohol. Selectivity to other products amounted to 67\% [13]. Another homogeneous catalyst, $p$-toluenesulfonic acid gave $17 \%$ yield of myrtanal together with 10\% myrtenol, 9\% perillylaldehyde and 8\% perillyl alcoholon [18]. Alternatively myrtanal was 
prepared in one-pot via oxidation of $\beta$-pinene with a homogeneous catalyst MnIIISalenCl: $\mathrm{H}_{2} \mathrm{O}$ giving a maximum conversion of $30 \%$ and $54 \%$ selectivity towards myrtanal [19]. Furthermore, myrtanal was obtained in the oxidation of $\alpha$-pinene using $\mathrm{SeO}_{2}$ as a catalyst [20]. After oxidation the $\mathrm{SeO}_{2}$ catalyst was reduced and filtered. Thereafter water was removed from the filtrate and finally the solution contained $49 \%$ myrtanal together with 31\% myrtenol.

In order to apply the principles of green chemistry, it is beneficial to use a solid, reusable acid catalyst. Different heterogeneous catalysts have been applied in the isomerization of $\beta$-pinene oxide in the literature. Unmodified alumina catalyst has proved to be active in the isomerization performed under reflux, giving myrtanal and myrtenol as main products, with selectivity towards myrtanal of $44 \%$ [21]. $\mathrm{NaOH}$ modified alumina exhibited a different product distribution: myrtanal, myrtenal, myrtenol and myrtanol; representing 6, 18, 28 and $48 \%$ of the product mixture, respectively [22]. The highest selectivity to myrtanal was $50 \%$ obtained with rare earth-modified $\mathrm{Al}_{2} \mathrm{O}_{3}$ at $80^{\circ} \mathrm{C}$ in benzene as a solvent at $63 \%$ conversion [15]. Metal modified mesoporous MCM-41 was also tested as a catalyst in this reaction. The introduction of $\mathrm{Sn}, \mathrm{Ti}$ or $\mathrm{Zr}$ strongly improved the activity of the pure-silica MCM-41. The Sn-MCM-41 mesoporous catalyst showed the best results in $\beta$-pinene isomerization using nitromethane as a solvent at $80^{\circ} \mathrm{C}$, with a selectivity towards myrtanal of 80\%. Increasing the Sn loading from 8.3 to 12.5 wt \% barely increased myrtanal selectivity. The catalyst was filtered after the reaction and reactivated by calcination, showing that the catalyst could be recycled without loss of activity and selectivity [13]. Myrtanal selectivity of $82 \%$ at complete conversion of $\beta$-pinene oxide was obtained with Sn-MCM-41 mesoporous catalyst and it decreased to $76 \%$ in the fourth catalytic test run [13]. Other heterogeneous catalysts investigated in the $\beta$-pinene oxide isomerization were Zr-Beta, Sn-Beta and Ti-Beta in different solvents [14]. The best result was obtained with the Zr-Beta catalyst in acetonitrile as a solvent, where selectivity towards myrtanal reached $94 \%$ at almost complete conversion of $\beta$-pinene after two hours at a reaction temperature of $80^{\circ} \mathrm{C}$. With the Sn-Beta catalyst, the selectivity to myrtanal in the same reaction conditions was $89 \%$. It should be pointed out here that Beta zeolite used in their work [14] did not contain any aluminium and thus it exhibited very low acidity [23]. It is reported that performing the reaction over Lewis acidic catalysts yielded myrtenal as the main product, whereas Brønsted acidity was responsible for the formation of myrtenol and perillyl alcohol. The reaction of $\beta$-pinene oxide performed over 
commercial nitrogen containing resins treated with Brønsted acids resulted in the formation of perillyl alcohol with a selectivity of $60 \%$, together with $10 \%$ of myrtenol.

The aim in this work was to synthesize, characterize and test Sn modified three different Beta zeolites with varying $\mathrm{Si}$ to $\mathrm{Al}$ ratio in the isomerization of $\beta$-pinene oxide and compare their performance with that of Sn-Y-12 zeolite catalyst. Catalysts were charaterized by several physico-chemicals methods, such as nitrogen adsorption, XPS, EXAFS, X-ray diffraction, scanning electron microscope, FTIR-pyridine and transmission electron microscope. Furthermore, reaction kinetics, which has not been investigated earlier in the isomerization of $\beta$-pinene oxide according to our knowledge, has now been investigated in detail.

\section{Experimental}

Catalysts applied for $\beta$-pinene oxide isomerization were three different Beta zeolite with varying $\mathrm{Si} / \mathrm{Al}$ ratios as well as $\mathrm{Y}$ zeolite ion-exchanged with an aqueous solution of $\mathrm{SnCl}_{2}$. Starting from the proton form, the catalysts were modified with Sn to obtain 3 wt\% of Sn using ion-exchange method. $0.4940 \mathrm{~g}$ of $\mathrm{SnCl}_{2}$ were dissolved in $500 \mathrm{ml}$ of distilled water and mixed with a magnetic stirrer. The $3 \mathrm{~g}$ of proton form zeolite was added into the solution and stirred at $200 \mathrm{rpm}$ during 48 hours. Then it was filtered in vacuum and washed with 2 liters of distilled water. After drying, the Sn-zeolite was calcined in a muffale oven at a rate of $3.7^{\circ} \mathrm{C} / \mathrm{min}$ up to $250^{\circ} \mathrm{C}$, maintaining the same temperature for $40 \mathrm{~min}$, followed by a heating rate of $3^{\circ} \mathrm{C} / \mathrm{min}$ up to $400^{\circ} \mathrm{C}$ and maintaining at $400^{\circ} \mathrm{C}$ during four hours, thereafter catalyst was cooled to $25^{\circ} \mathrm{C}$.

\subsection{Catalyst characterization methods}

The X-ray powder diffraction measurements were performed using the instrument Philips X'Pert Pro MPD. It has a Bragg-Brentano diffraction geometry and it was operated with monochromated $\mathrm{CuK} \alpha$ radiation at $40 \mathrm{kV} / 50 \mathrm{~mA}$. The primary $\mathrm{X}$-ray beam was collimated with a fixed $0.25^{\circ}$ divergence slit and a fixed $20 \mathrm{~mm}$ mask. A $0.25^{\circ}$ fixed anti-scatter slit and a programmable receiving slit set at $0.20 \mathrm{~mm}$ were used in the diffracted beam side prior to the proportional counter. All samples were measured using the same plastic sample holder. The measuring range of $1.15^{\circ}-90^{\circ}$ and a scanning speed of $0.04^{\circ} / 2 \mathrm{~s}$ were used. 
The measured diffractograms were analyzed with Philips X'Pert HighScore and MAUD programs [24]. HighScore was used for the phase analysis and MAUD for the Rietveld refinement. The crystal structures of the zeolites were retrieved from IZA website [25]. The reference X-ray powder diffraction pattern was calculated using the corresponding Crystallographic Information File (CIF) of Beta zeolite.

The SEM analysis was performed with a LEO Gemini 1530 with a Thermo Scientific UltraDry Silicon Drift Detector (SDD), equipped with SE (secondary electron), BSE backscattered electron) detectors, as well as an In-Lens detector. Transmission electron microscope images were taken with an apparatus TEM, LEO 912, Omega.

To determine the specific surface area and the pore size distribution, nitrogen adsorption was performed on the catalyst sample (Sorptomatic 1900, Carlo Erba Instrument). The surface area was calculated using Dubinin's equation, due to the microporosity of the zeolites. Around $0.16 \mathrm{~g}$ of catalyst were outgassed for 3 hours at $150^{\circ} \mathrm{C}$ to eliminate any water that may be present. Nitrogen (AGA, 99.999\%) was adsorbed and desorbed from the sample, cooled at $-196^{\circ} \mathrm{C}$. The spent catalyst samples were outgassed for 3 hours at a lower temperature, $120^{\circ} \mathrm{C}$, to eliminate the water molecules but preventing at the same time the removal of the organic compounds that are adsorbed on the spent catalyst.

The acidity of the catalysts was measured by infrared spectroscopy (ATI Mattson FTIR) using pyridine ( $\geq 95 \%$, A.R.) as a probe molecule. This allows to differentiate Brønsted and Lewis acid sites and measure the amount present in the sample. The amount of Brønsted and Lewis acid sites were calculated from the intensities of the corresponding spectral bands, $1545 \mathrm{~cm}^{-1}$ and $1450 \mathrm{~cm}^{-1}$ respectively, using the molar extinction parameters previously reported by Emeis [26].

XAS measurements were carried out at HASYLAB (DESY in Hamburg, Germany) on the beamline X1 (Fe K-edge, $29200 \mathrm{eV}$ ) using a double-crystal Si(311) monochromator, which was detuned to $65 \%$ of maximum intensity to exclude higher harmonics in the X-ray beam. The spectra were recorded in the transmission mode at liquid nitrogen temperature. For the measurements ca. $100 \mathrm{mg}$. of each sample were loaded to the cylindrical cell with $13 \mathrm{~mm}$ inner diameter and $5 \mathrm{~mm}$ thickness. Aluminum foil made windows were used for the measurements at Sn $K$ edge. All spectra were measured simultaneously with the reference spectrum of Sn foil placed between second and third ionisation chambers, so that the absolute energy calibration is performed. The spectra of $\mathrm{Sn}$ foil, $\mathrm{SnO}$ and $\mathrm{SnO}_{2}$ which were used as 
references, were collected at the room temperature. All spectra were measured 2 times to ensure their reproducibility.

Analysis of the EXAFS spectra was performed with the software VIPER for Windows [27]. In the spectra of the absorption coefficient $\mu$, a Victorian polynomial was fitted to the pre-edge region for background subtraction. A smooth atomic background $\mu_{0}$ was evaluated using a smoothing cubic spline. The Fourier analysis of the $\mathrm{k}^{2}$-weighted experimental function $\chi=\left(\mu-\mu_{0}\right) / \mu_{0}$ was performed with a Kaiser window. The required scattering amplitudes and phase shifts were calculated by the $a b$ initio FEFF8.10 code [28] for $\alpha-\mathrm{Fe}_{2} \mathrm{O}_{3}$. The fitting was done in the $k$ - and r-spaces. The shell radius $r$, coordination number $N$, DebyeWaller factor $\sigma^{2}$ and adjustable "muffin-tin zero" $\Delta E$ were determined as fitting parameters. The errors of the fitting parameters were found by decomposition of the statistical $\chi^{2}$ function near its minimum, taking into account maximal pair correlations.

The photoemission spectra were measured using a Perkin-Elmer PHI 5400 spectrometer with a monochromatized $\mathrm{Al} \mathrm{K \alpha} \mathrm{X}$-ray source that was operated at $14 \mathrm{kV}, 300 \mathrm{~W}$. The analyzer pass energy was $17.9 \mathrm{eV}$ and the energy step was $0.1 \mathrm{eV}$. The vacuum chamber base pressure was $10^{-9} \mathrm{mbar}$. Charge neutralizer was necessary to use and its power was set so that Si 2p peak was at $103.5 \mathrm{eV}$, corresponding to $\mathrm{SiO}_{2}$ binding energy. The studied peaks were Sn 3d, Fe 2p, Si 2p and Al 2p. Also, a 1400 - $0 \mathrm{eV}$ survey spectrum was taken for each sample. The step length was $0.5 \mathrm{eV}$ and peaks were calibrated using $\mathrm{BE}$ of $\mathrm{SiO}_{2}$ which is $103.3-103.7 \mathrm{eV}$.

TGA analysis was carried out from some spent catalysts using DSC-TGA (Q Series instrument) with the following temperature programme: $25^{\circ} \mathrm{C}-600^{\circ} \mathrm{C}$ under nitrogen flow of $100 \mathrm{ml} / \mathrm{min}$.

\subsection{Isomerization of $\beta$-pinene oxide: Kinetic experiments}

Isomerization of $\beta$-pinene oxide was performed in a glass reactor using toluene as solvent at $70^{\circ} \mathrm{C}$ under argon. Prior to the experiments, catalysts were dried at $100^{\circ} \mathrm{C}$ for at least five hours prior to the reaction to eliminate water. In other experiments, catalysts were activated in the glass reactor at $250^{\circ} \mathrm{C}$ in an inert atmosphere for $30 \mathrm{~min}$ before the isomerization reaction.

The initial (+)- $\beta$-pinene oxide (80+\%, Advanced technology \& Industrial Company Ltd. RM B1F) concentration was $0.012 \mathrm{~mol} / \mathrm{l}$ and toluene (JT Baker) was used as a solvent. The catalyst mass was $75 \mathrm{mg}$. The isomerization of $\beta$-pinene was performed in the kinetic regime by applying a large stirring rate of $410 \mathrm{rpm}$ and using catalyst particles below $63 \mu \mathrm{m}$. 
The samples taken at different times from the batch reactor were analyzed by gas chromatography. The column used was a HP wax bonded polyethylene glycol column, with a capillary of $30 \mathrm{~m} \times 250 \mu \mathrm{m} \times 0.25 \mu \mathrm{m}$ nominal, $250^{\circ} \mathrm{C}$ as the maximum temperature allowed (Agilent 19091X-133). The identification of products was performed by mass spectra-gas chromatography using a DB-Petro column with a capillary of $50 \mathrm{~m}$ x $200 \mu \mathrm{m} \times 0.50 \mu \mathrm{m}$ nominal, maximum $325^{\circ} \mathrm{C}$ (Agilent 128-1056). The following chemicals were used to calibrate the GC-mehod: p-cymene, free of terpenes (90+\%, Fluka), L-carveol, cis- and transmixture (95+\%, ), (1R)-(-)-myrtenol (95+\%, Safc) and (S)-(-)-perillyl alcohol (90+\%, Safc).

\section{Results and discussion}

\subsection{Catalyst characterization results}

EDX analysis were applied both for fresh and spent catalysts. Sn-content was determined with EDX analysis and it varied from 2.4 - 3.4 wt.\% (Table 1). The EDXA elemental analysis of the fresh and spent Sn-Beta 300 catalysts revealed that the mass ratio of Sn to Si was about 0.076 and it remained constant when comparing fresh and spent catalyst. This result indicates that no leaching of tin occurred during $\beta$-pinene oxide isomerisation. Furthermore, sulphur, chloride or phopshorus were not detected in the spent catalysts.

Specific surface areas of the catalysts are shown in Table 2. The increased acidity of the catalysts decreased the specific surface areas in Beta zeolites, whereas the specific surface area of zeolite $\mathrm{Y}$ was the highest. In addition to the measurements of the specific surface areas of the fresh catalysts, also the specific surface area of the spent catalyst, SnBeta-300 was determined. The results showed that during 360 min reaction time the specific surface area decreased from $808 \mathrm{~m}^{2} / \mathrm{g}$ to $142 \mathrm{~m}^{2} / \mathrm{g}$ indicating that coking is one reason for lowered reaction rates after prolonged reaction times (see Section 3.2.2). After regeneration with air at $400^{\circ} \mathrm{C}$ for two hours it was possible to recover the specific surface area up to $92 \%$ indicating the zeolites which tolerate relatively high temperatures, are promising catalysts for fine chemical applications.

Diffractograms of Sn-Y and Sn-Beta-300 zeolite catalysts are shown in Fig. 2a and b. Diffractogram of Beta zeolite shows the typical patterns reported in literature [29]. XRDmeasurements revealed that the zeolite structure was intact. SnO could not be observed at $30^{\circ}$ and $33^{\circ}$ [30] neither for $\mathrm{SnO}_{2} 26.5,38.7$ and 51.7 [31]. 
TEM images showed the regular periodicity of pores in Beta and Y zeolites and highly dispersed Sn particles (Fig. 3). The pores of Y and Beta zeolites were intact after the Sn modifications.

SEM images showed that the studied Sn-Y, Sn-Beta-25, Sn-Beta-150 and Sn-Beta-300 catalysts in isomerization of $\beta$-pinene exhibited morphology typical for $\mathrm{Y}$ and Beta zeolites (Fig. 4 a, b, c and d). Sn-Y-12 crystals were polygonal, whereas Sn-Beta-300 and Sn-Beta25 crystals were spherical.

The Brønsted acid site concentrations decreased in the following order: Sn-Beta-25 $>$ Sn-Y > Sn-Beta-75 > Sn-Beta-300. Furthermore, Sn-Beta-25 catalyst exhibited the highest Lewis acid site concentration (Table 3). The concentration of Lewis acid sites increased with Sn-modification for all other catalysts but not for Sn-Beta-150.

Oxidation state of Sn in three catalysts, namely Sn-Y, Sn-Beta 300 and Sn-Beta-25 was studied by XPS and the Sn 3d5/2 peaks are depicted in Fig. 5. The binding energies for $\mathrm{Sn}^{0}, \mathrm{Sn}^{2+}$ and $\mathrm{Sn}^{4+}$ of Sn 5d3/2 XPS exhibit BE-values of 485.03, 486.8 and $487.16 \mathrm{eV}$, respectively according to [34]. The relative amount of different tin species showed that the largest difference was the high amounts of low oxidation state Sn in Sn-Beta-300-IE, which was also the most selective catalyst in isomerization of $\beta$-pinene oxide (see Section $3.2)$.

EXAFS results are shown in Fig. 6. Sn $K$ XANES of samples were compared with reference compounds: $\mathrm{Sn}$ foil, $\mathrm{SnO}$ and $\mathrm{SnO}_{2}$ (Fig. 6a). The spectra of both Sn-Zeolite samples are quite different from $\mathrm{Sn}$ foil and $\mathrm{SnO}$ and resemble spectrum of $\mathrm{SnO}_{2}$. The Fourier transformation of EXAFS oscillations of Sn samples and references are presented in Fig. 6b. In the spectrum of $\mathrm{SnO}_{2}$ the first peak corresponds to first and second coordination shells, containing $4 \mathrm{O}$ atoms at $2.052 \AA$ and $2 \mathrm{O}$ atoms at $2.057 \AA$ real distances from central Sn atom, whereas the second peak corresponds the third coordination shell, containing $2 \mathrm{Sn}$ atom at $3.186 \AA$ real distance from central Sn atom. In both spectra of samples under study peak at about $1.5 \AA$ uncorrected distance is developed. In the spectrum of Sn-Beta-300 sample long-range order structure consisting of two prominent peaks at about 2.9 and $3.5 \AA$ uncorrected distance is observed as well. The EXAFS spectrum of Sn-Beta-25 sample does not have any hints for $\mathrm{SnO}_{2}$ structure with long-range order formation - there are only minor peaks above $r=2.8 \AA$. Thus it can be concluded that the $\mathrm{Sn}$ in Sn-Beta-300 is resembling $\mathrm{SnO}_{2}$. 


\subsection{Evaluation of catalysts in isomerization of $\beta$-pinene oxide}

\subsubsection{Qualitative kinetics}

Since kinetics of $\beta$-pinene oxide isomerization has not been studied earlier, a typical kinetic curve for this reaction is depicted in Fig. 7. The isomerization reaction was carried out over Sn-Beta-300 at $70{ }^{\circ} \mathrm{C}$ for $360 \mathrm{~min}$. using toluene as a solvent. The three main products formed over Sn-Beta-300 catalyst at conversion of $85 \%$ were myrtanal, perillyl alcohol and myrtenol with the molar ratios of 35: 5: 12.5: 1 . Due to the relatively low acid site concentration, the reaction rate of this catalyst lowered with increasing reaction time. It is noteworthy to mention that with Sn-Beta-300 catalyst the concentration of myrtanal increased with increasing reaction time, whereas the formation rate of other products was close to zero after $180 \mathrm{~min}$. (Fig. 7). When the concentration of acid sites was increased, complete conversion of $\beta$-pinene oxide was achieved in less than $30 \mathrm{~min}$.

\subsubsection{Effect of catalyst acidity and structure on the isomerization of $\beta$-pinene oxide}

A comparative study of the performance of four different catalysts, namely Sn-Beta with three different $\mathrm{Si} / \mathrm{Al}$ ratios and $\mathrm{Sn}-\mathrm{Y}$ in $\beta$-pinene isomerization was performed. The reason for selecting Beta and Y zeolite structures were relatively large pores, suitable for fine chemical applications. Beta zeolite exhibits a three dimensional structure with the following channel sizes: $0.76 \times 0.64,0.76 \times 0.64$ and $0.55 \times 0.56 \mathrm{~nm}$ [35], whereas Y-zeolite has $0.74 \mathrm{~nm}$ pores and also three dimensional strucutre. Both these zeolites are made of 12 membered rings.

The highest initial isomerization rate was achieved with Sn-Y zeolite catalyst, which also exhibited the highest $\mathrm{Br}_{\lrcorner}$nsted acidity (Table 5) and the initial rate declined with decreasing concentration of acid sites. Thus with the catalyst exhibiting the lowest acidity, namely SnBeta-300, only 72 \% conversion was achieved in $120 \mathrm{~min}$. The isomerization rate declined with increasing time, whereas after 6 hours the conversion was $87 \%$. One of the reasons for decrease in isomerization rate was coke deposition, which was confirmed with the lowered specific surface area (see seciton 3.1).

In the isomerization of $\beta$-pinene oxide the two main products are myrtanal and perillyl alcohol. The ratio between the initial formation rates of perillyl alcohol to myrtanal was 
plotted against the total concentration of either Brønsted or Lewis acid sites in three different Sn-Beta catalysts (Fig. 9). It can be stated from this picture that increased concentration of both Brønsted and Lewis acid sites concentration in the catalyst increased this ratio indicating that higher the acid site concentration, the higher is the formation rate of perillyl alcohol.

Product selectivities over Sn modified Beta and $\mathrm{Y}$ zeolite catalysts were also investigated. The most selective catalyst towards the formation of myrtanal was mild acidic Sn-Beta-300 catalyst (Fig. 8b, Table 5), exhibiting the selectivity of $66 \%$ at $72 \%$ conversion of $\beta$-pinene oxide. The selectivity remained the same during next 4 hours, when the conversion increased to $87 \%$, i.e. after 360 min total reaction time. This result indicates that the low amounts of both Brønsted and Lewis acid sites catalyzed formation of myrtanal. In comparison to literature the highest reported selectivity to myrtanal was achieved in the ismoerzaiton of $\beta$-pinene oxide at $80^{\circ} \mathrm{C}$ in nitromethane as a solvent over Sn-Beta zeolite catalyst [14]. The Sn-Beta catalyst did not contain aluminium and thus its acidity was very low [23]. The highest selectivity to perillyl alcohol was achieved over the catalyst with the largest amount of $\mathrm{Br}_{\lrcorner}$nsted acid sites. i.e. Sn-Beta-25. Furthermore, this catalyst promoted formation of other products with prolonged reaction times. Thus it was concluded that one of the reasons for the highest selectivity to myrtanal over Sn-Beta-300 catalyst was attributed to the states of $\mathrm{Sn}$ i.e. lowest content of metallic $\mathrm{Sn}^{0}(13 \%)$ and the highest content of $\mathrm{Sn}^{2+}(70$ \%), Table 4. EXAFS analysis exhibited the presence of $\mathrm{Sn}$ as $\mathrm{SnO}_{2}$ in $\mathrm{Sn}-\mathrm{Beta}-300$ catalyst.

From the mechanistic point of view kinetics was studied via plotting the concnetraitons of different products versus each other in order to reveal the reaction network. When plotting the concentrations of myrtenal against myrtanal as well as perillyl alcohol versus myrtanal, it is observed that both formation of myrtenol and perillyl alcohol were enhanced with increasing Brønsted acidity of the catalyst (Fig. 8c, d), but they seemed to be formed parallel on the same type of sites with the same ratio independent of the concentration of acid sites (Fig. 8e). In addition, it was shown that when using myrtenol as a reactant, the main product was not perillyl alcohol, but other isomers with the molecular mass of 152 $\mathrm{g} / \mathrm{mol}$ indicating analogously to the kinetic analysis that myrtenol and perillyl alcohol were formed in parallel. Analogous results were achieved when reacting myrtenol with either $\mathrm{HCl}$ or $\mathrm{HNO}_{3}$ exhibiting that perillyl alcohol was not formed from myrtenol [13].

\subsubsection{Effect of temperature on the isomerization of $\beta$-pinene oxide}


Effect of temperature was studied in the isomerization of $\beta$-pinene oxide in the temperature range of $27-70^{\circ} \mathrm{C}$ over Sn-Y zeolite catalyst (Fig. 10). The initial isomerization rate increased as expected with increasing temperature and the activation energy was calculated from Arrhenius equation to be $40 \mathrm{~kJ} / \mathrm{mol}$. Complete conversion of $\beta$-pinene oxide was achieved already after $20 \mathrm{~min}$ at $70^{\circ} \mathrm{C}$, whereas at $50^{\circ} \mathrm{C}$ and $27^{\circ} \mathrm{C}, 92 \%$ and $57 \%$ conversions were reached in $260 \mathrm{~min}$. and in $1440 \mathrm{~min}$., respectively.

The highest concentration of myrtanal was obtained at $70^{\circ} \mathrm{C}$, when the isomerization rate was the highest (Fig. 10b). On the other hand, when lower reaction temperature was used, much lower concentraitons of myrtanal were produced. The selectivity to myrtanal increased also with increasing reaction temperature (Table 6). Noteworthy to mention, that with very acidic Sn-Y zeolite catalyst also large amounts of other products were formed, thus lowering the selectivity to myrtanal. Additionally it is also clear from Fig. $10 \mathrm{c}$ that the concentration of perillyl alcohol was slightly enhanced compared to the concentration of myrtanal at a lower temperature. This result suggests that when isomerization occurs rapidly, the formation of myrtanal is promoted. Myrtanal selectivity increased with increasing conversion as depicted in Fig. 10d. Generally, however, it can be concluded that in this temperature range the effect of temperature was relatively minor on the product distribution.

\section{Conclusions}

Beta zeolite catalyst with three different $\mathrm{Si} / \mathrm{Al}$ ratios together with $\mathrm{Y}$ zeolite were modified with Sn. The catalysts were characterized with several techniques, such as pyridine desorption by FTIR, XRD, TEM, SEM, XPS and EXAFS and their catalytic performances were studied in $\beta$-pinene oxide isomerization. The phases of zeolite catalysts were identified by XRD to be either Beta zeolite or Y zeolite with their characteristic peaks. The zeolite structures remained intact after Sn modification. All the studied catalysts contained both Brønsted and Lewis acid sites. Sn modifications increased Lewis acidity in all catalysts except Sn-Beta-150. Sn was not visible in either XRD or TEM due to the presence of finely dispersed Sn particles loaded via ion-exchange. XPS measurements exhibited the presence of $\mathrm{Sn}^{2+}, \mathrm{Sn}^{4+}$, and $\mathrm{Sn}^{0}$, in all the Sn modified Beta and Y zeolite catalysts. The highest amount of $\mathrm{Sn}^{2+}(70 \%)$, was obtained in Sn-Beta-300 and metallic $\mathrm{Sn}^{0}$ (67.4 \%) in Sn-Y zeolite catalysts. The EXAFS studies showed the presence of $\mathrm{Sn}$ as $\mathrm{SnO}_{2}$ in Sn-Beta-300 catalyst. 
Kinetics of $\beta$-pinene isomerization was studied over four different Sn modified catalysts. In $\beta$-pinene oxide isomerization the main products were myrtanal, peillyl alcohol and myrtenal. In addition to these products also other isomers with the same molecular weight of $152 \mathrm{~g} / \mathrm{mol}$ were formed. The isomerization rate increased with increasing catalyst acidity. Complete conversion of $\beta$-pinene oxide was achieved with Sn-Y, Sn-Beta-25 and Sn-beta150 , whereas only $56 \%$ conversion was obtained within 1440 min with the catalyst exhibiting the lowest acidity, namely Sn-Beta-300.

Kinetic studies of the production of the three main products revealed that the formation of perillyl alcohol and myrteneol were both enhanced with increasing the amount of acid sites, whereas myrtanal formation was catalyzed by catalyst exhibiting low amount of acid sites. Furthermore, parallel formation of myrtenol and perillyl alcohol was observed being independent on the amount of acid sites. This result indicated that these two products are fromed on the similar surface sites. Additionally the experiments starting with myrtenol as a reactant revealed that only small amounts of perillyl alcohol were formed, and the dominating products were other isomers. Catalyst with the low acid site concentration and with the highest amount of $\mathrm{Sn}^{2+}$ was the most selective catalyst giving $66 \%$ selectivity to myrtanal at $72 \%$ conversion at $70^{\circ} \mathrm{C}$ in toluene. The lowest selectivity to myrtanal, $38 \%$ was on the other hand was achieved with the most acidic Sn-Beta-25 zeolite catalyst at high conversion levels, since the amount of other isomers was enhanced. The effect of temperature in the range of $27-70^{\circ} \mathrm{C}$ revealed that reaction rate was enhanced as expected. The activation energy was $40 \mathrm{~kJ} / \mathrm{mol}$. Selectivity to myrtanal increased with increasing conversion. The product distribution was not significantly affected by variation in temperature.

\section{References:}

1. Mäki-Arvela P, Simakova I L, Murzin D Yu (2012) Catalytic transformaiton of extractives, Wiley. 
2. Drew J Pylant, G D (1966) Tappi 49: 430-438.

3. Kimland B, Norin, T., (1972) Svensk Papperstidning, 75: 403-409.

4. Costa V V, da Silva Rocha K A, de Sousa L F, Robles-Dutenhefner P A, Gusevskaya E V, (2011) J Mol Catal A: Chem 345: 69-74.

5. Kaminska J, Schwegler M A, Hoefnagel A J, van Bekkum H (1992) Recl Trav Pays-Bas (1992) 432-437.

6 Gervasini A, Messi C, Carniti P, Ponti A, Ravasio N, Zaccheria F. (2009) J Catal 262: 224234.

7. Ravasio N, Zaccheria F, Gervasini A, Messi C (2008) Catal Commun 9: 1125-1127.

8. Neri G, Rizzo G, Crisafulli C, De Luca L, Donato A, Musolino M G, Pietropaolo R (2005) Appl. Catal A: Gen 295: 116-125.

9. Alaerts L, Seguin E, Poelman H, Thibault-staryk F, Jacobs P A, De Vos D, (2006) Chem. Eur. J 12: 7353-7363.

10. Kunkeler, P.J., van der Waal J C, Bremmer J, Zuurdeeg B J, Downing R S, van Bekkum H (1998) Catal Lett 53: 135-138.

11. Hölderich W F, Heitmann G, (1997) Catal Today 38: 227-233..

12. Ravindra D B, Nie Y T, Jaenicke S, Chuah G K, Catal Today 96: 147-153.

13. Corma A, Renz M, Susarte M (2009) Top Catal 52: 1182-1189.

14. Torre O, Renz M, Corma A (2010) 380: 165-171 .

15. Jayasree J, and Narayanan, CS (1995) Bull Chem Soc Jpn 68: 89-94.

16. Chastain, D E, Sanders, W E Jr, Sanders, C C (1992) US patent 5110832.

17. Chastain, D E, Mody, N, Majetich, G (1999) US patent, 5994598.

20. Kuchin A A, Frolova L L, Dreval I V, Panteleeva M V, Alekseev I N, Ru 2176994 C1, 2000.

19. Gomes M F, Antunes, OA (1996) Catal Lett 42: 213-215.

21. Kergomard A, Philibert-Bigou J. (1959) Bull Soc Chim Fr. 1381.

22. Joshi, VS, Dev S (1977) Tetrahedron 33: 2955-2957.

23. Bare S R, Kelly S D, Sinkler W, Low J J, Modica F S, Valencia S, Corma A, Nemeth L T, (2005) J Am Chen Soc 127: 12924-12932.

24. MAUD program. (http://www.ing.unitn.it/ maud/). [Online] [Cited: 06 06, 2012.]

25. International Zeolite Asociation. (http://www.iza-online.org/). [Online] [Cited: 06 06, 2012.]

26. Emeis, C A J Catal (1993) 141, 347-354. 
27 K.V.Klementiev,

VIPER

for

Windows,

freeware, www.cells.es/Beamlines/CLAESS/software/viper.html; Klementev K V (2001) J Phys D Appl Phys 34, 209-217.

28. Ankudinov A L, Ravel, B, Rehr J J, Conradson, C D (1998) Phys Rev B 58 : 7565-7576.

Peterson, P. E., Grant, G (1991) J Org Chem 56: 16-20.

29. Guo W, Xiong C, Huang L, Li Q (2001) J Mater Chem 11: 1886-1890.

Alam N, Mojaya R, (2010) Energy \& Env Sci 3: 1773-1781.

30. SnO XRD this reference I have not found!

31. Farrukh M A, Heng B-T, Adnan R. (2010) Turk J Chem 34: 537 - 550.

32. Aho A, Kumar N, Eränen K, Salmi T, Hupa M, Murzin D Yu (2007) IChem E part B, Safety and Env. Prot. 85: 473-480.

33. Aho A, Kumar N, Eränen K, Salmi T, Holmbom B, Hupa M, Murzin D Yu (2010) Fuel 89: 1992-2000.

34. Luo J, Chao, C (1990) J Nano-crystalline solids, 119: 37-40.

35. Baerlocher Ch, Meier W M, Oslon D H, Atlas of zeolite framework types, fifth ed. Elsevier science, Amsterdam, 2001. 

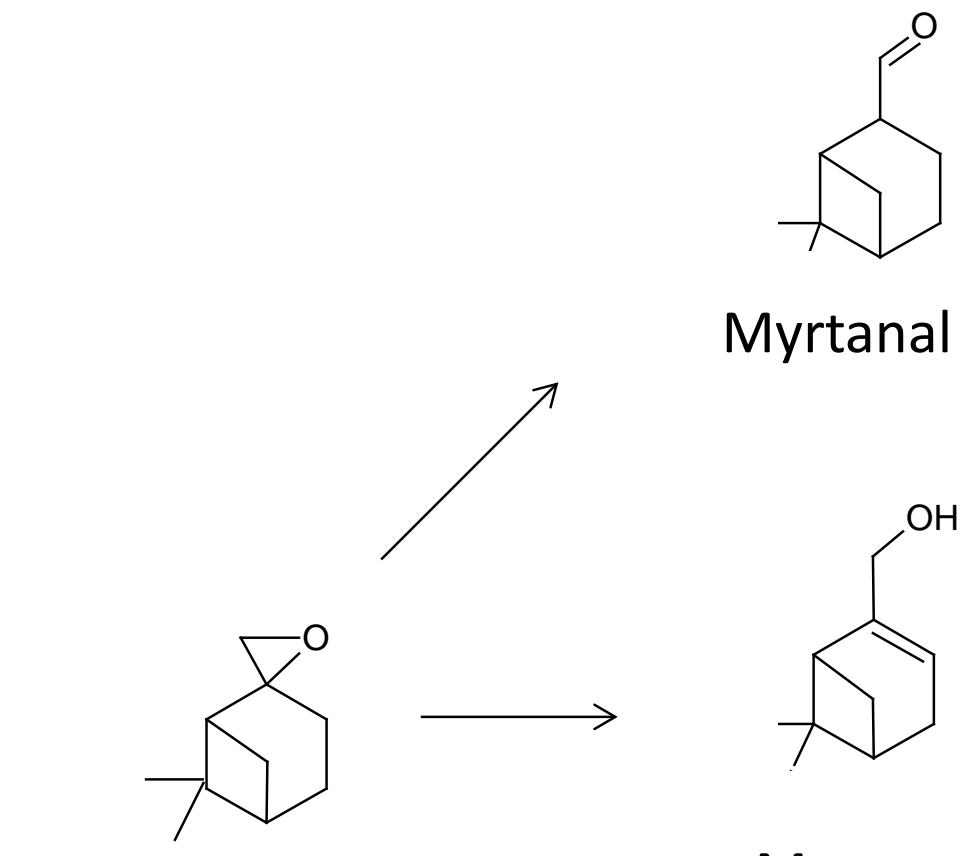

Myrtanal
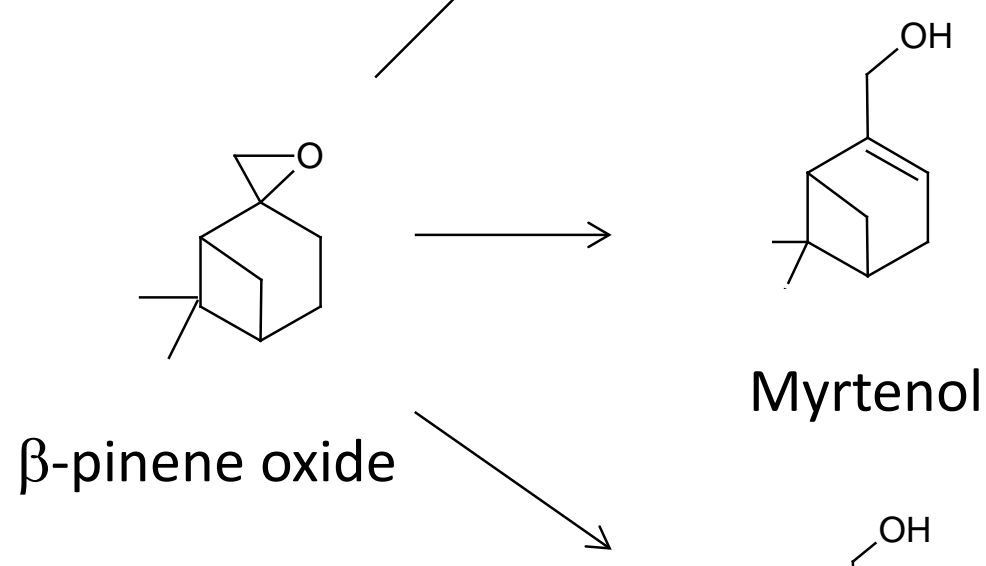

Myrtenol

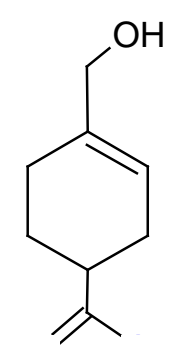

Perillyl alcohol

Fig. 1. Reaction scheme for isomerizaiton of $\beta$-pinene oxide. 
a)

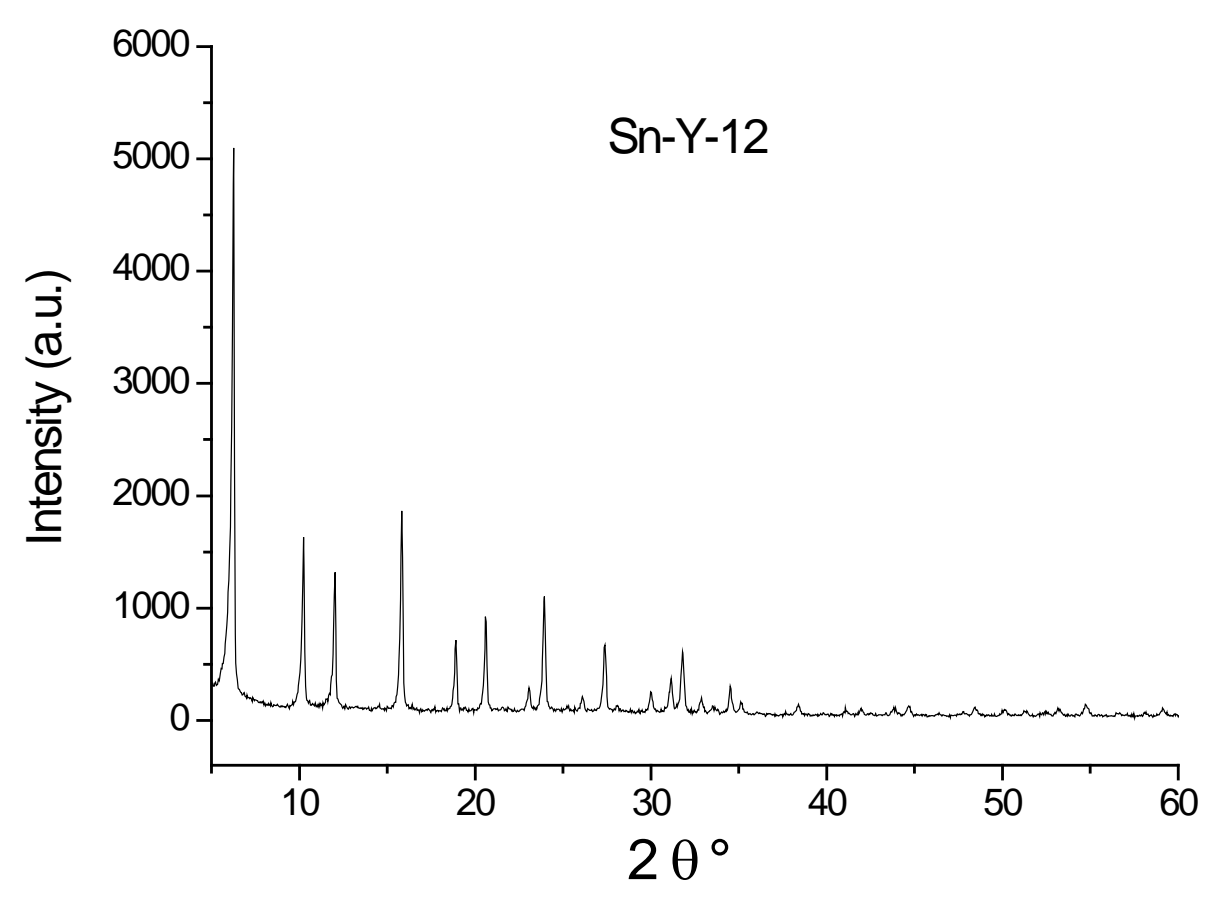

b)

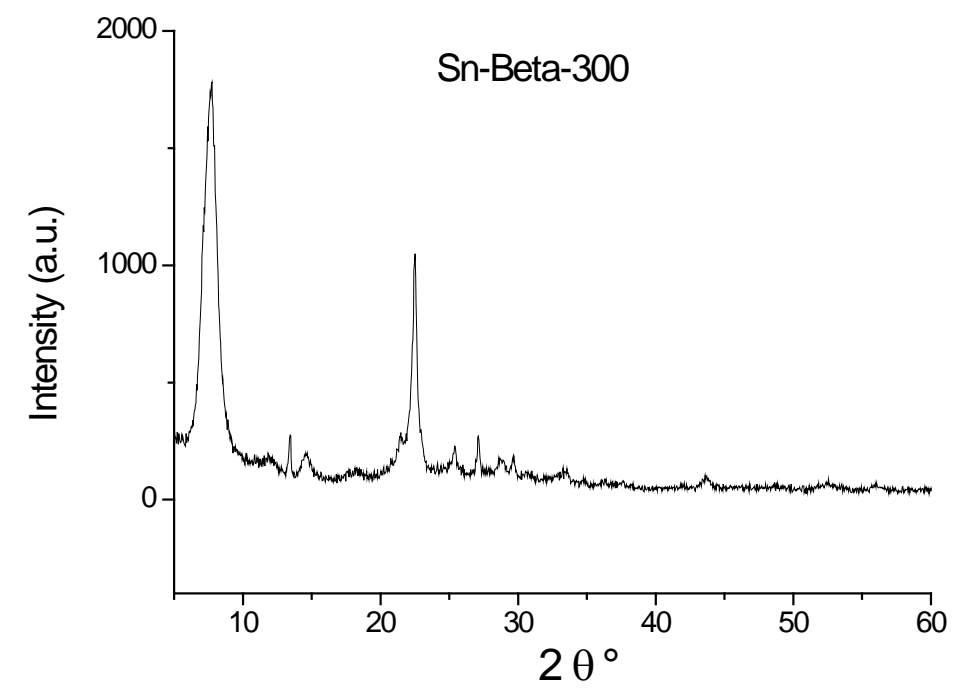

Fig. X-ray powder diffraction patterns Sn Y (a) and Sn-Beta-300 (b). 
a)

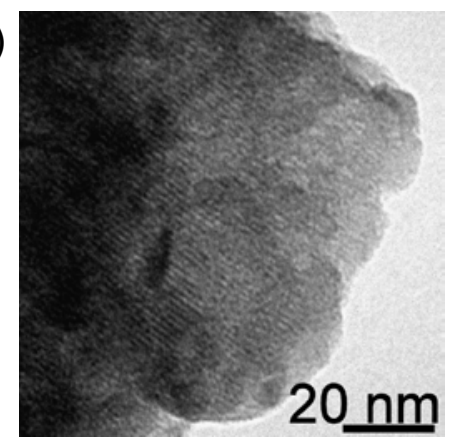

b)

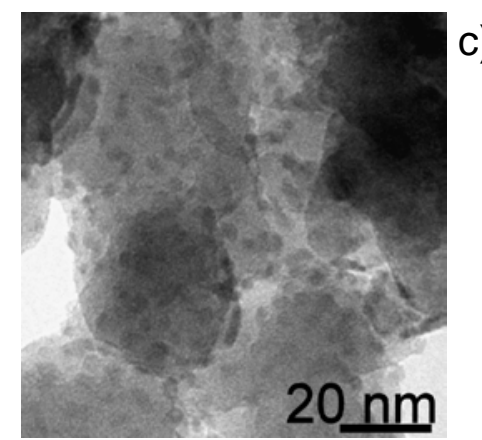

c)

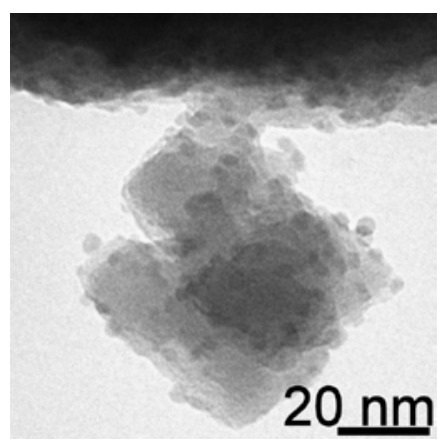

Fig. 3. TEM images of a) Sn-Y, b) Sn-Beta-25 and c) Sn-Beta-300.
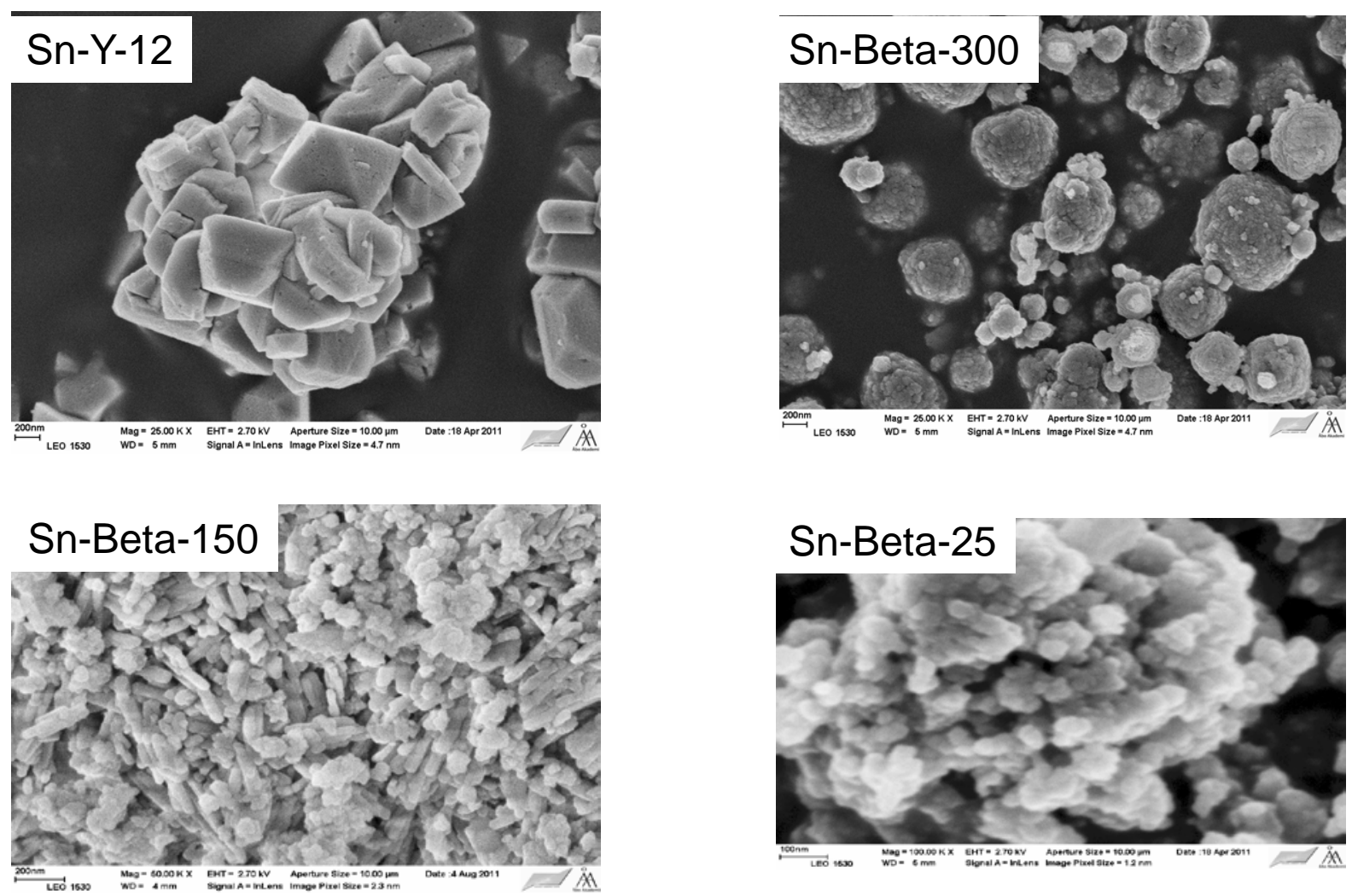

Fig. 4. SEM images of four different Sn-modified Beta and Y zeolites. 


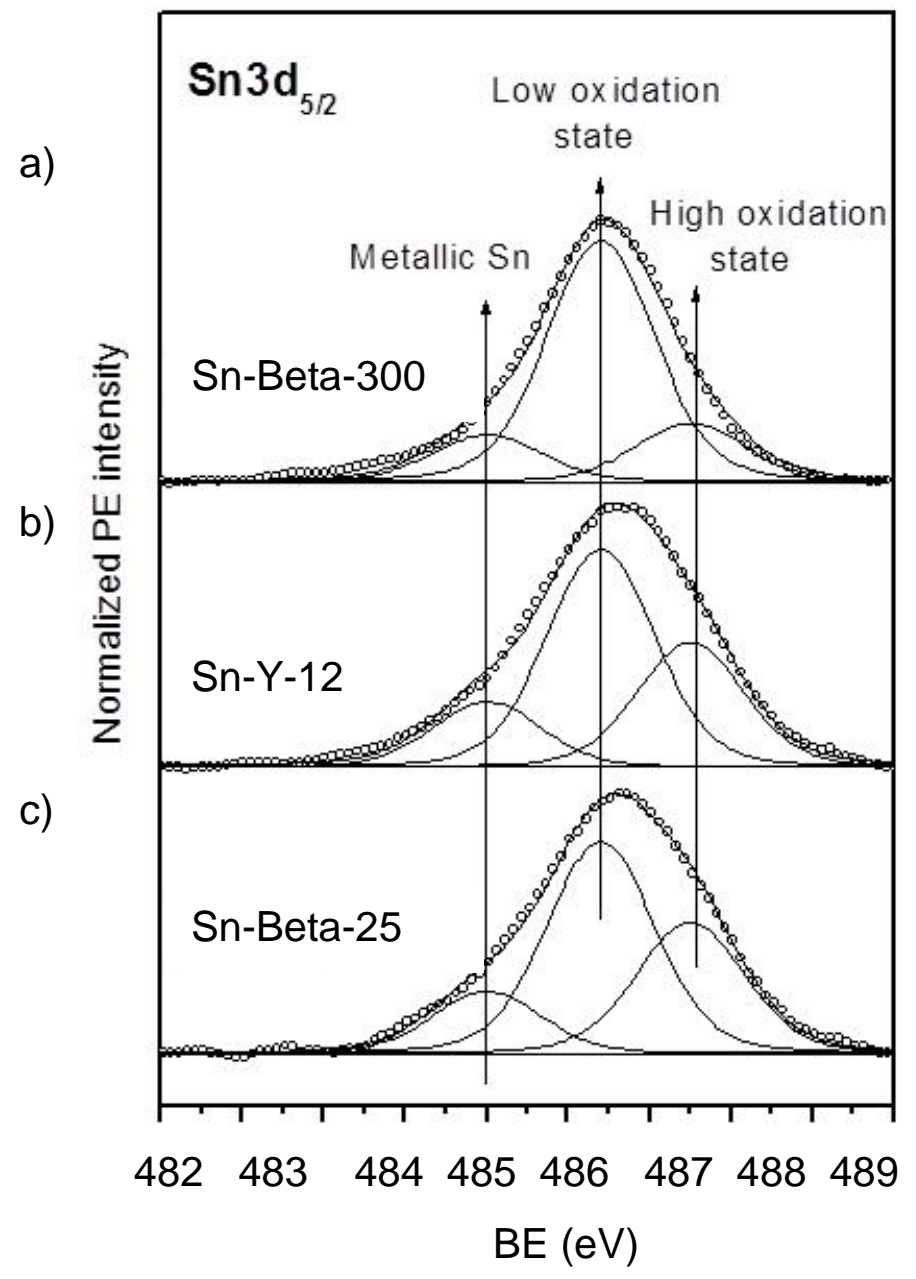

Fig. 5. XPS of Sn 3d5/2 of a) Sn-Beta-300, b) Sn-Y and c) Sn-Beta-25. 
a)

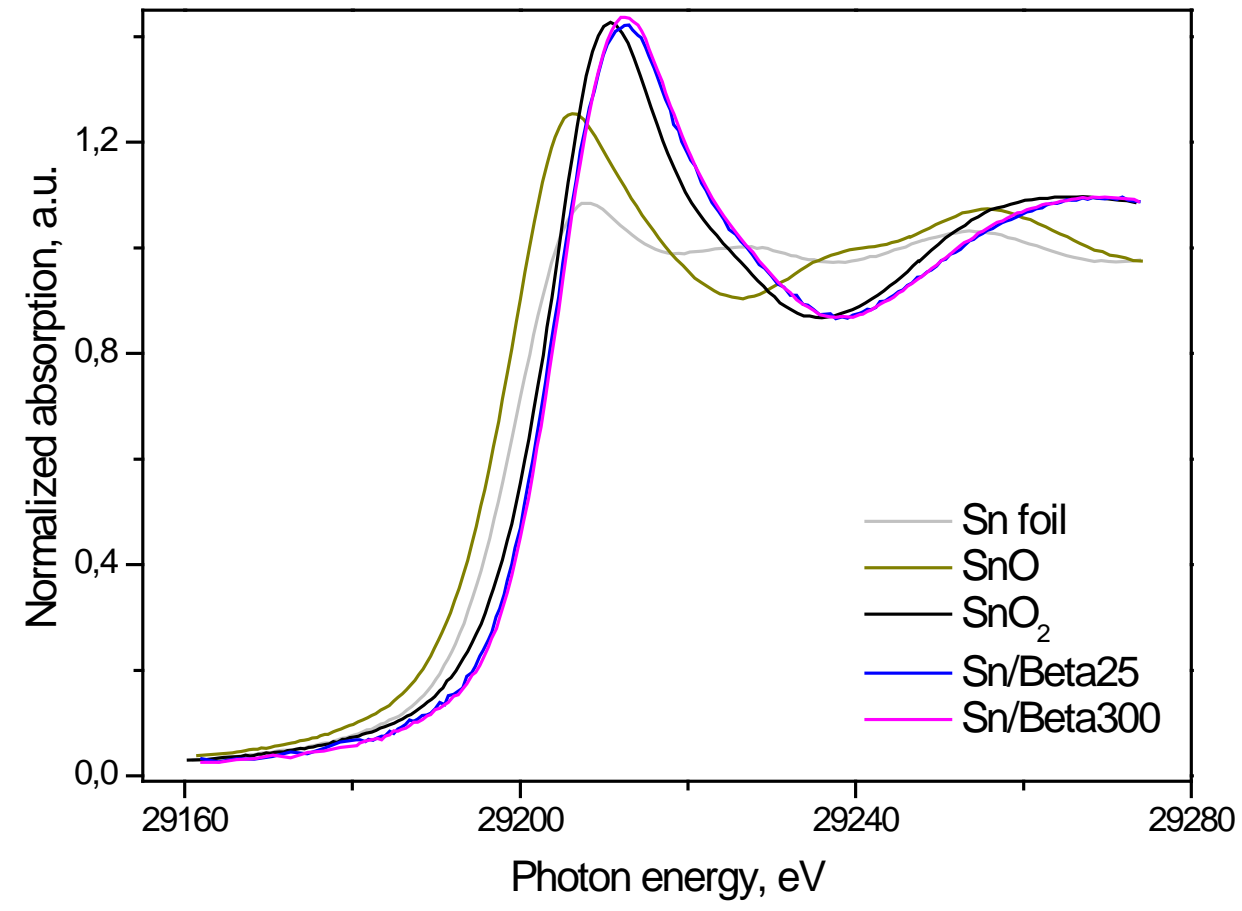

b)

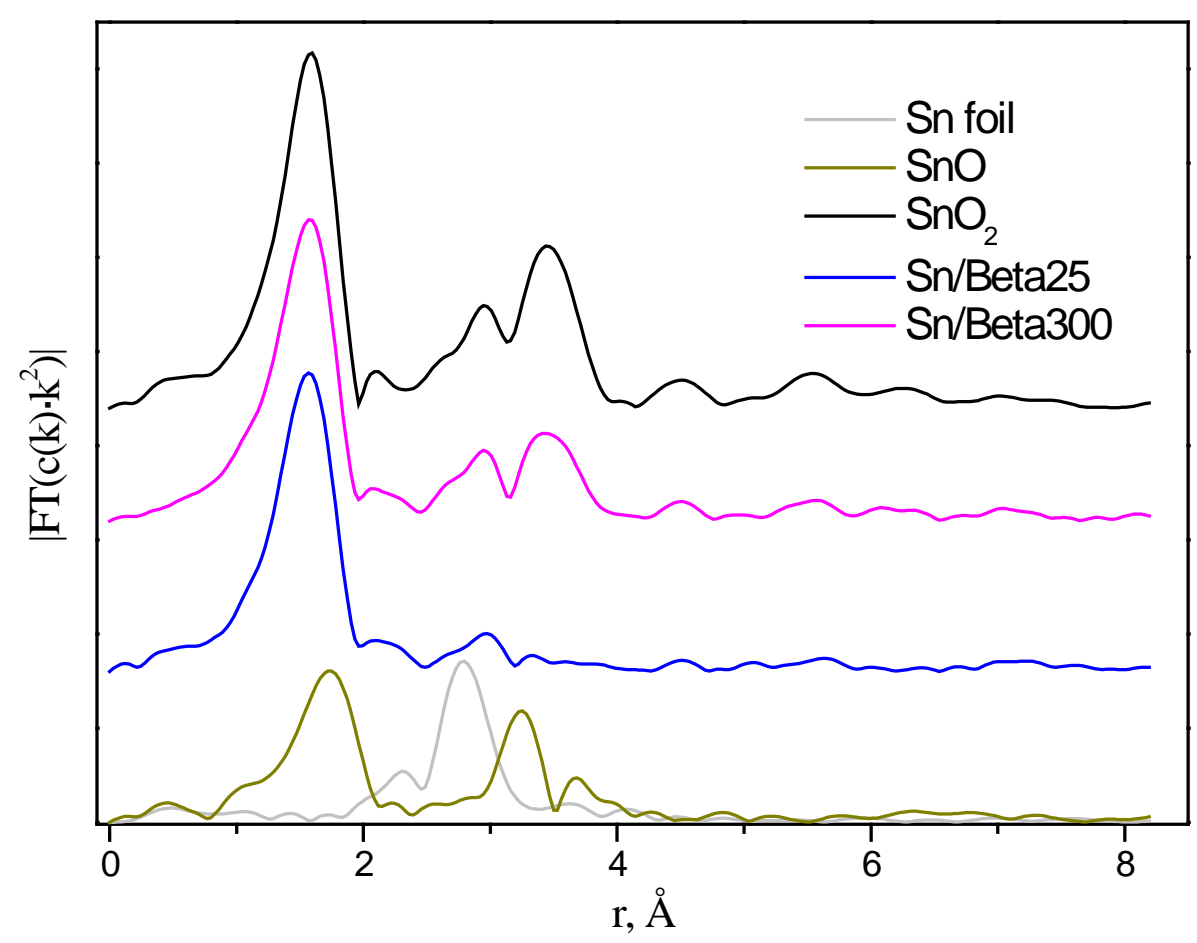

Fig. 6. a) Sn K XANES and b) EXAFS spectra (modulus of Fourier-transformed k2-weightned spectra) of Sn-containing Beta zeolites compared with reference compounds 


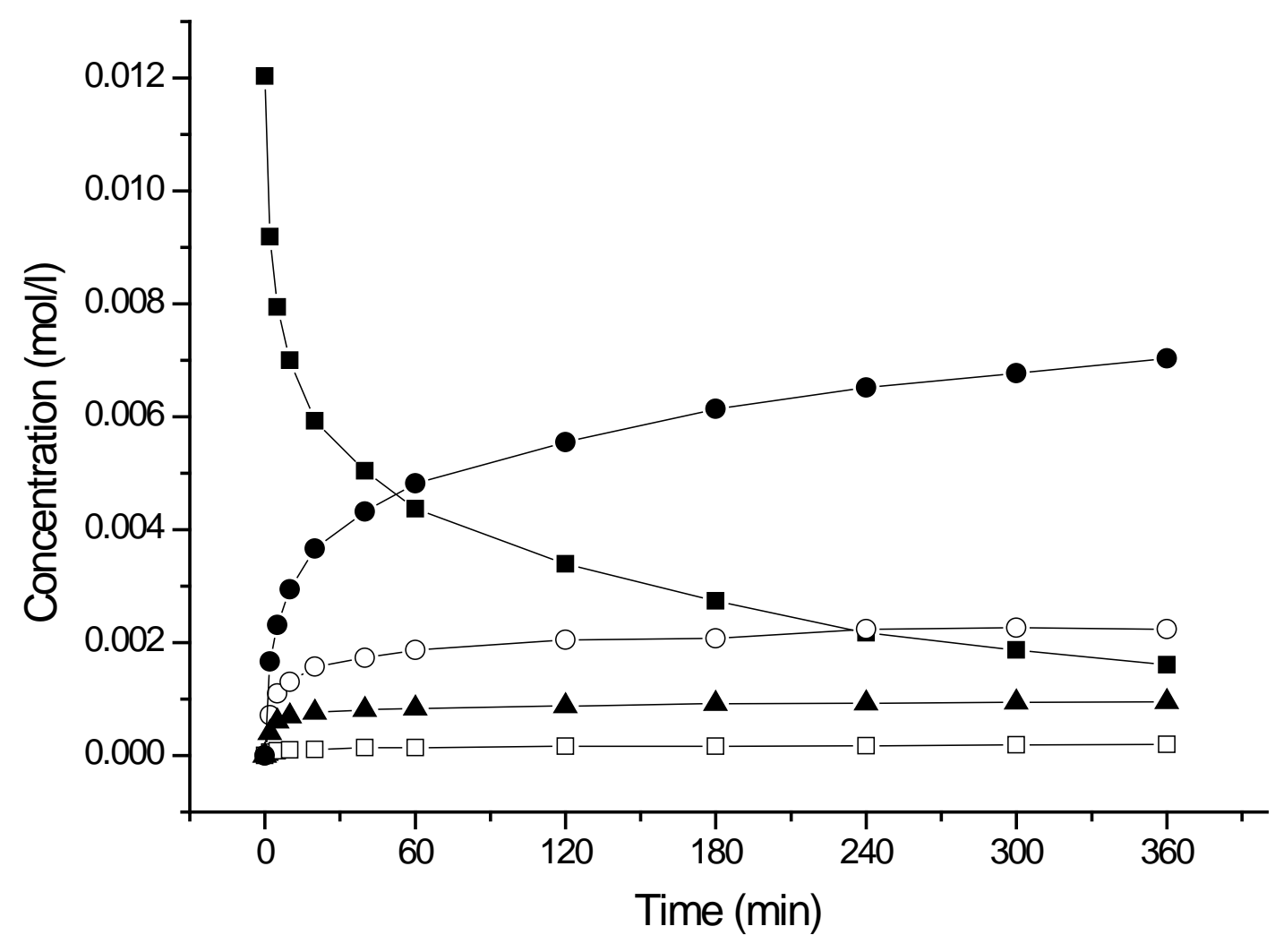

Fig. 7. Kinetics in isomerization of $\beta$-pinene oxide as a function of time at $70^{\circ} \mathrm{C}$ in toluene over Sn-Beta-300 catalyst at $70^{\circ} \mathrm{C}$ in toluene. Symbols: $(\square) \beta$-pinene oxide, (X) myrtanal, (>) perillyl alcohol, $(\sim)$ myrtenol and (o) other isomers with the molecular weight of $152 \mathrm{~g} / \mathrm{mol}$. 
a)

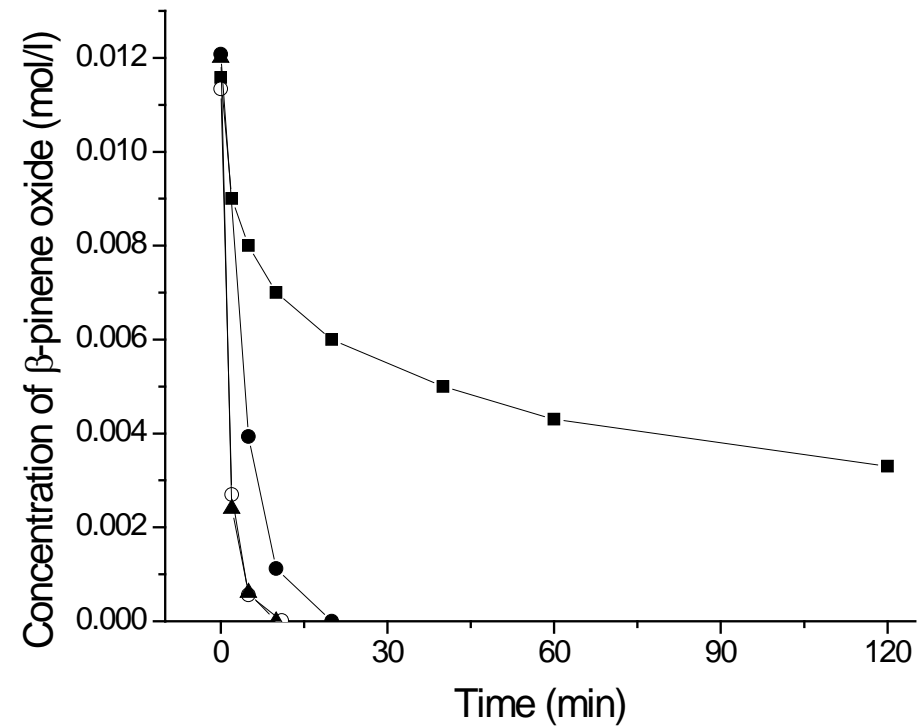

b)

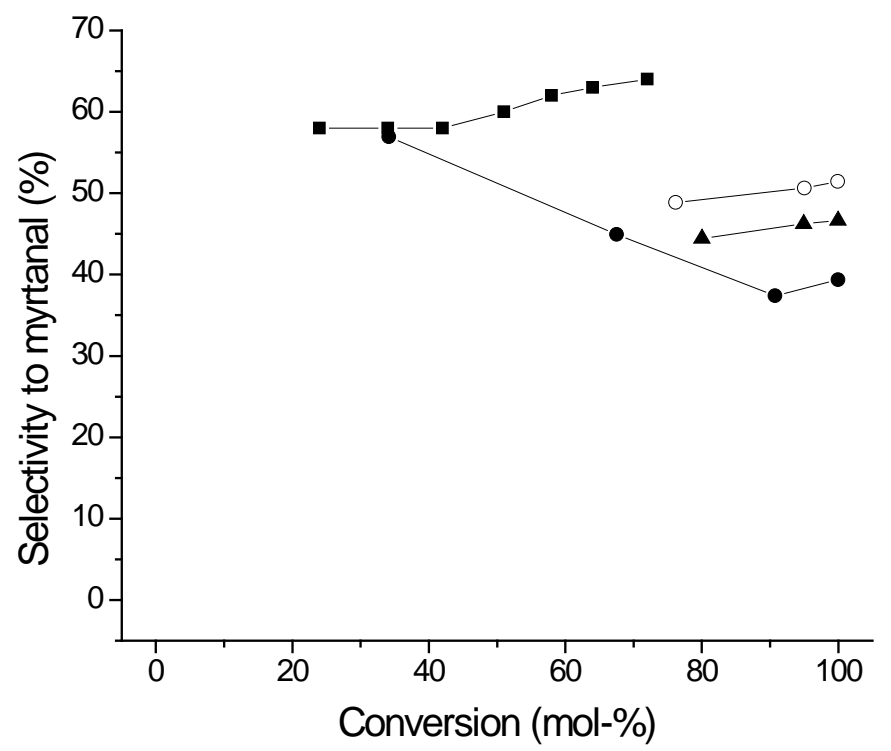


c)

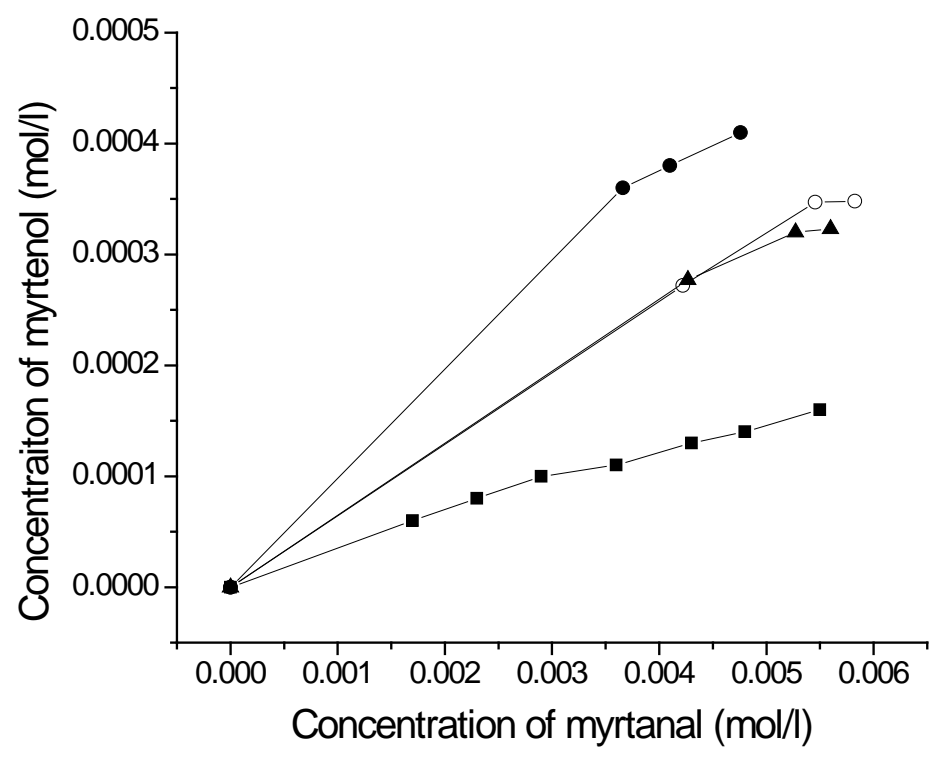

d)

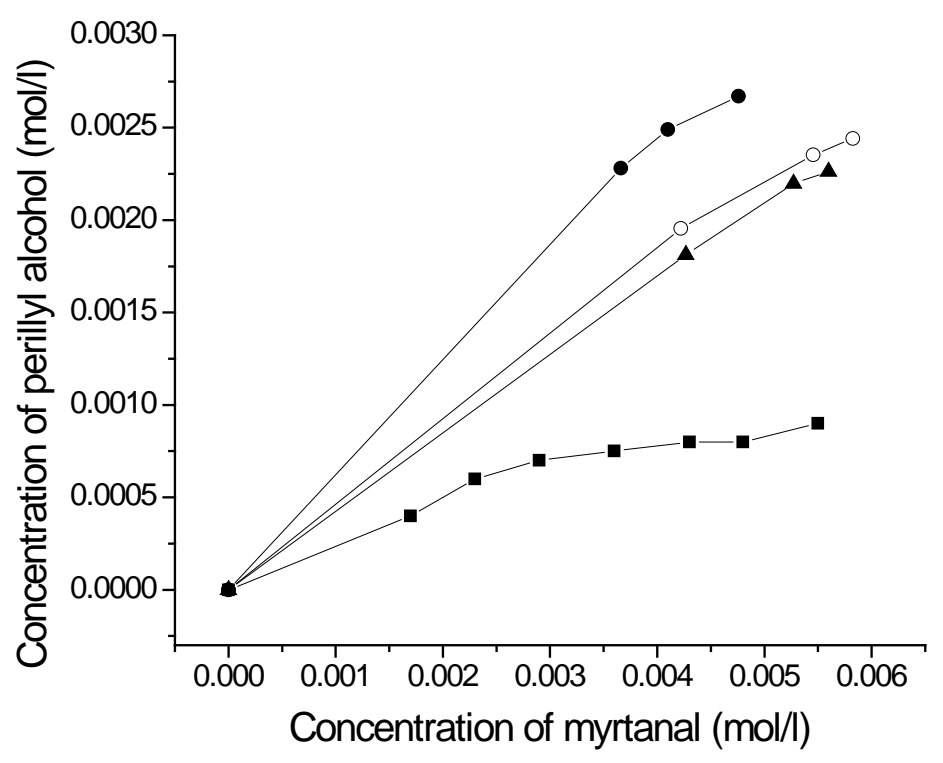




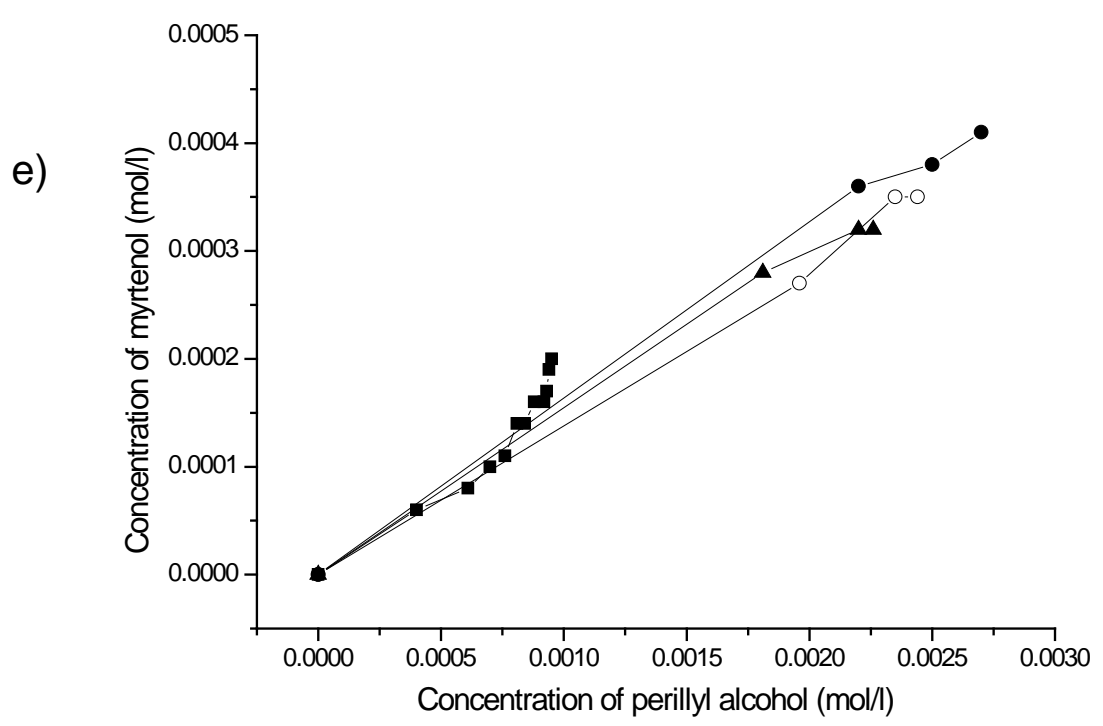

Fig. 8. Concentration of a) $\beta$-pinene oxide, b) selectivity to myrtanal, c) concentration of myrteneol, d) períllyl alcohol as a function of the concentration of myrtanal and e) concentration of myrtenol as a function of the concentration of perillyl alcohol at $70^{\circ} \mathrm{C}$ in toluene. Symbols: ( $\square$ ) Sn-Beta-300, (o) Sn-Beta-150, (X) Sn-Beta-25 and (>) Sn-Y.

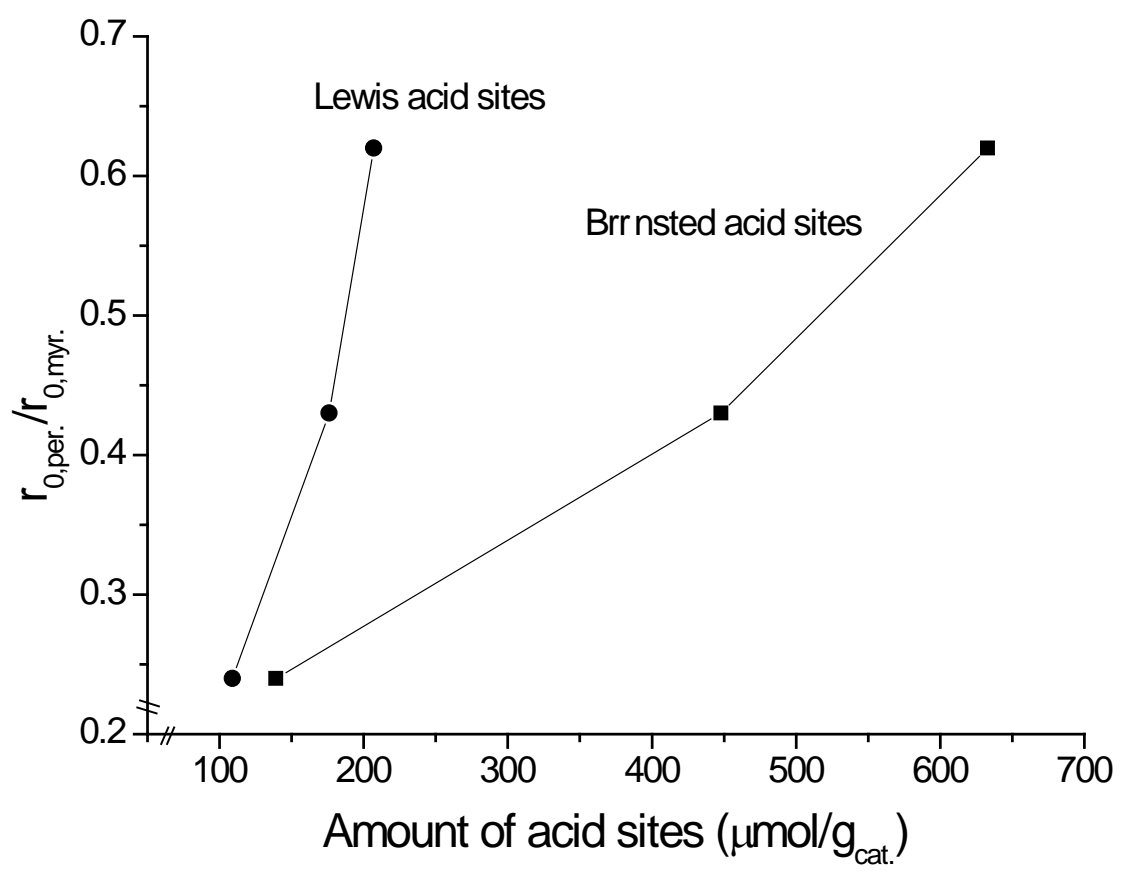

Fig. 9. The ratio between the initial formation rates of perillyl alcohol to myrtanal as a function of the amount of Brønsted and Lewis acid sites in Sn-modified Beta-25, Beta-150 and Beta-300. 


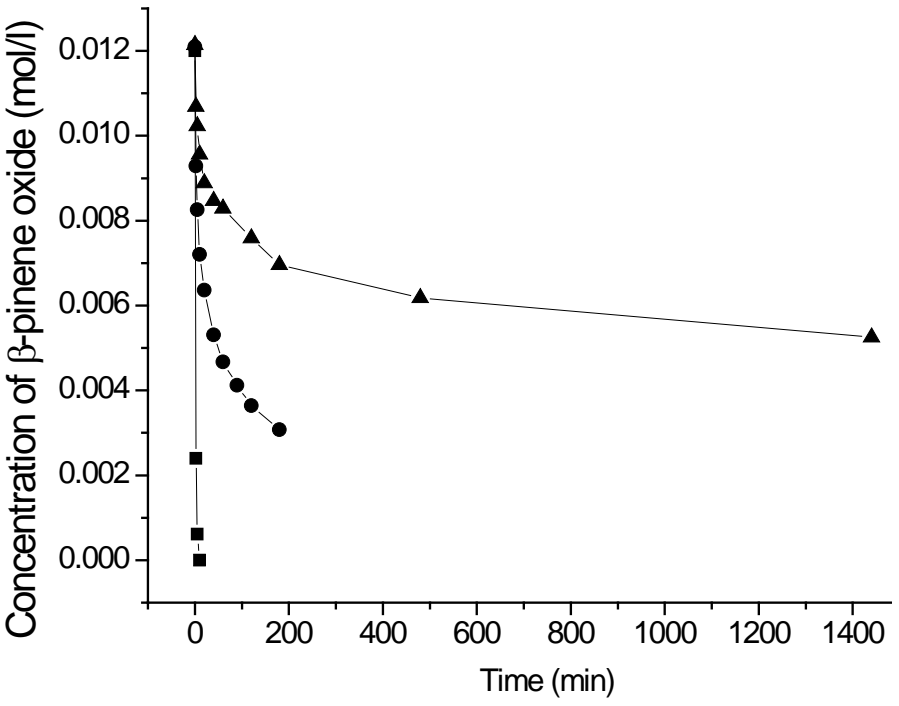

b)

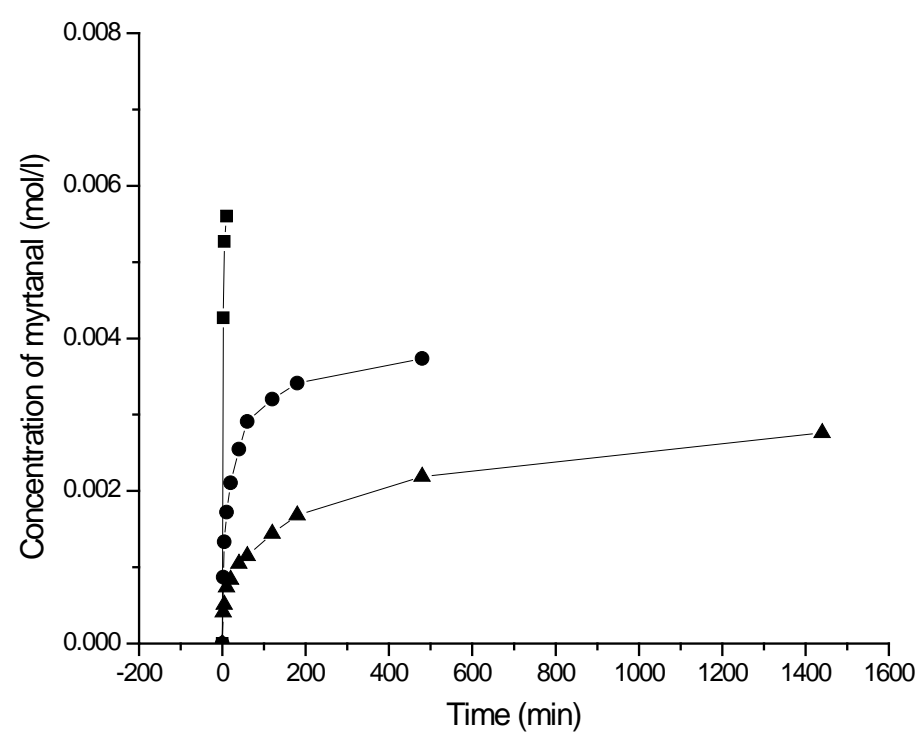


c)

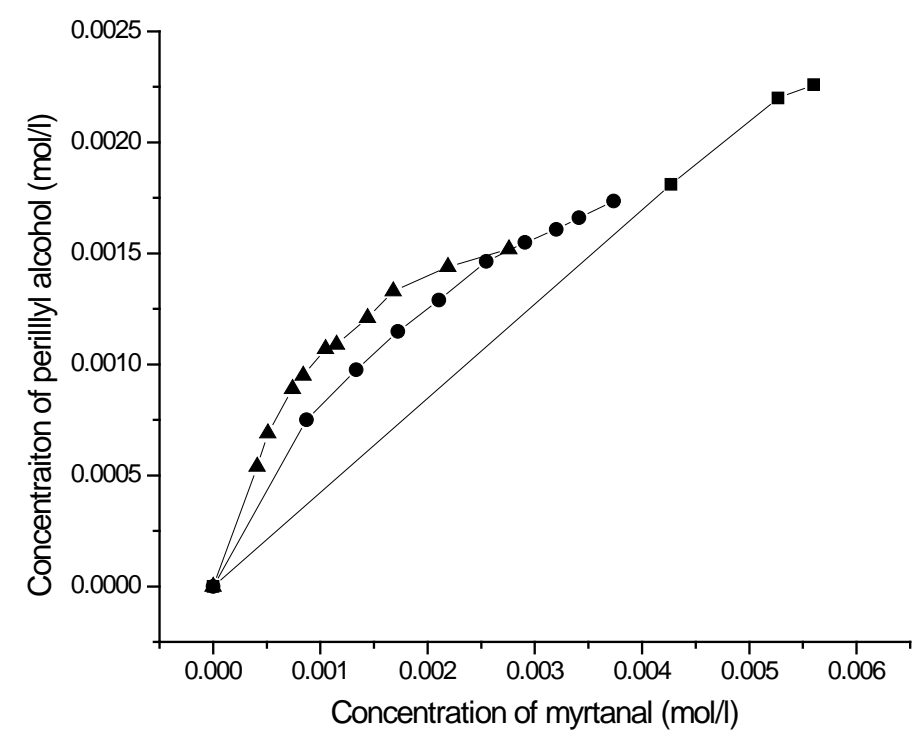

d)

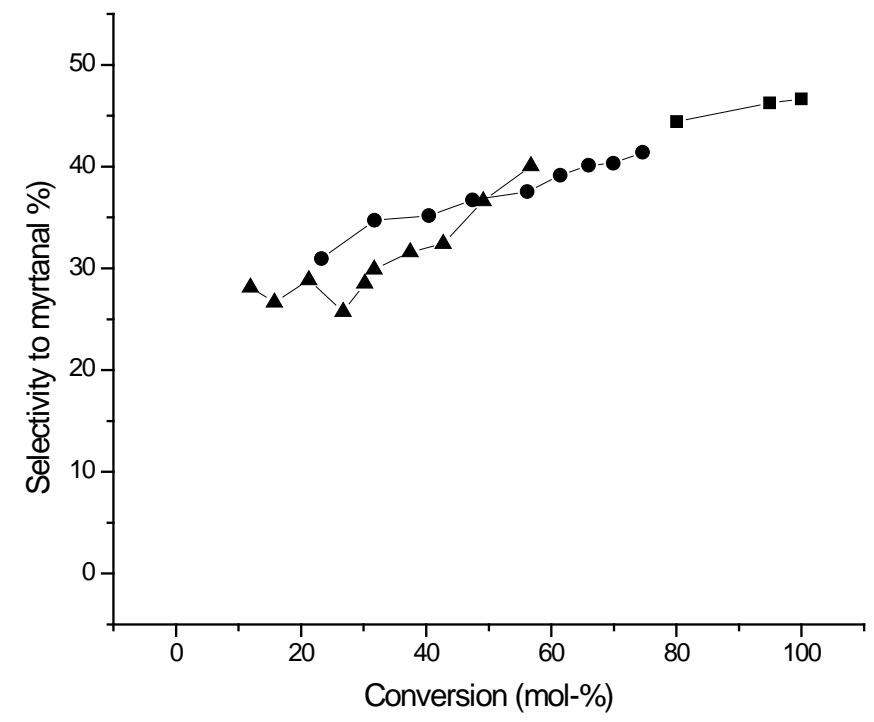

Fig. 10. Effect of temperature in the isomerization of $\beta$-pinene oxide over Sn-Y catalyst using toluene as solvent a) the concentration of $\beta$-pinene oxide, b) concentration of myrtanal, c) concentration of perillyl alcohol versus concentration of myrtanal, and d) selectivity to myrtanal versus conversion of $\beta$-pinene oxide. Symbols: $27^{\circ} \mathrm{C}(>), 50^{\circ} \mathrm{C}(\mathrm{X})$ and $70^{\circ} \mathrm{C}(\square)$. 
Table 1. Sn loading in Beta and $\mathrm{Y}$ zeolites determined by energy dispersive $\mathrm{X}$-ray micro analysis.

\begin{tabular}{cc}
\hline Catalyst & Metal loading (wt\%) \\
\hline Sn-Beta-300-IE & 2.8 \\
Sn-Beta-150-IE & 3.2 \\
Sn-Beta-25-IE & 2.4 \\
Sn-Y-12-IE & 3.0 \\
\hline
\end{tabular}

Table 2. Specific surface area of the Sn-modified Beta and Y zeolites

\begin{tabular}{ccc}
\hline Catalyst & Specific surface area $\left(\mathrm{m}^{2} / \mathrm{g}\right)$ & Micropore volume $\left(\mathrm{cm}^{3} / \mathrm{g}\right)$ \\
\hline Sb-Beta-300-IE & 808 & 0.287 \\
Sn-Beta-150-IE & 696 & 0.239 \\
Sn-Beta-25-IE & 674 & 0.247 \\
Sn-Y-12-IE & 1011 & 0.359 \\
\hline
\end{tabular}


Table 3. Brønsted and Lewis acid site concentration determined by pyridine adsorptiondesorption (FTIR).

\begin{tabular}{|c|c|c|c|c|c|c|}
\hline \multirow[t]{2}{*}{ Catalyst } & \multicolumn{3}{|c|}{ Brønsted acid sites $(\mu \mathrm{mol} / \mathrm{g})$} & \multicolumn{3}{|c|}{ Lewis acid sites ( $\mu \mathrm{mol} / \mathrm{g})$} \\
\hline & $250^{\circ} \mathrm{C}$ & $350^{\circ} \mathrm{C}$ & $450^{\circ} \mathrm{C}$ & $250{ }^{\circ} \mathrm{C}$ & $350{ }^{\circ} \mathrm{C}$ & $450^{\circ} \mathrm{C}$ \\
\hline H-Beta-25 [31] & 219 & 187 & 125 & 82 & 43 & 25 \\
\hline Sn-H-Beta-25 & 263 & 213 & 157 & 114 & 63 & 27 \\
\hline H-Beta-150 [31] & 217 & 178 & 102 & 125 & 63 & 30 \\
\hline Sn-H-Beta-150 & 205 & 148 & 95 & 115 & 49 & 12 \\
\hline H-Beta-300 [31] & 54 & 49 & 23 & 28 & 9 & 4 \\
\hline Sn-H-Beta-300 & 57 & 55 & 27 & 76 & 26 & 7 \\
\hline H-Y-12 [32] & 242 & 205 & 89 & 84 & 17 & 3 \\
\hline Sn-H-Y-12 & 207 & 178 & 93 & 91 & 30 & 6 \\
\hline
\end{tabular}

Table 4. XPS analysis results from Sn $3 d_{5 / 2}$.

\begin{tabular}{cccc}
\hline Catalyst & Metallic $\mathrm{Sn}^{0}(\%)$ & $\begin{array}{c}\text { Low oxidation } \\
\text { state } \mathrm{Sn}^{2+}(\%)\end{array}$ & $\begin{array}{c}\text { High oxidation state } \\
\mathrm{Sn}^{4+}(\%)\end{array}$ \\
\hline Sn-Beta-300-IE & 13 & 70 & 17 \\
Sn-Beta-150-IE & 15 & 52 & 33 \\
Sn-Y-12-IE & 67.4 & 0.247 & 30
\end{tabular}


Table 5. Initial rates and selectivities to different products at 80 mol-\% conversion level at $70^{\circ} \mathrm{C}$, in parenthesis $50^{\circ} \mathrm{C}$.

\begin{tabular}{|c|c|c|c|c|c|}
\hline Catalyst & $\begin{array}{l}\text { Initial rate } \\
\text { (mmol/ } \\
\text { min/g) }\end{array}$ & $\begin{array}{l}\text { Myrtanal } \\
\text { selectivity } \\
\text { (mol-\%) }\end{array}$ & $\begin{array}{l}\text { Myrtenol } \\
\text { selectivity } \\
\text { (mol-\%) }\end{array}$ & $\begin{array}{l}\text { Perillyl } \\
\text { alcohol } \\
\text { (mol-\%) }\end{array}$ & $\begin{array}{c}\text { Other } \\
\text { products } \\
\text { (mol\%) }\end{array}$ \\
\hline Sn-Beta-300 & 2.8 & $66^{\mathrm{a}}$ & $2^{a}$ & $10^{\mathrm{a}}$ & $22^{\mathrm{a}}$ \\
\hline Sn-Beta-150 & $8.6(6.0)$ & $48(43)$ & $3(3)$ & $22(20)$ & 27 \\
\hline Sn-Beta-25 & $8.0(6.0)$ & 40 (35) & $4(4)$ & $25(25)$ & 31 \\
\hline Sn-Y & 9.6 & 43 & 3 & 19 & 35 \\
\hline
\end{tabular}

${ }^{\mathrm{a}} 72 \%$ conversion

Table 6. Initial rates and selectivities to different products at $50 \%$ conversion over Sn-Y catalyst.

\begin{tabular}{|c|c|c|c|c|c|}
\hline $\begin{array}{c}\text { Temperature } \\
\left({ }^{\circ} \mathrm{C}\right)\end{array}$ & $\begin{array}{l}\text { Initial rate } \\
\text { (mmol/ } \\
\text { min/g) }\end{array}$ & $\begin{array}{l}\text { Myrtanal } \\
\text { selectivity } \\
\text { (mol-\%) }\end{array}$ & $\begin{array}{l}\text { Myrtenol } \\
\text { selectivity } \\
\text { (mol-\%) }\end{array}$ & $\begin{array}{l}\text { Perillyl } \\
\text { alcohol } \\
\text { (mol-\%) }\end{array}$ & $\begin{array}{c}\text { Other } \\
\text { products } \\
\text { (mol-\%) }\end{array}$ \\
\hline 27 & 1.6 & 37 & 2 & 24 & 37 \\
\hline 50 & 4.1 & 40 & 2 & 20 & 38 \\
\hline 70 & 9.6 & 43 & 3 & 19 & 35 \\
\hline
\end{tabular}


